\title{
Identification and Transcriptional Analysis of Priming Genes in Arabidopsis thaliana Induced by Root Colonization with Pseudomonas chlororaphis 06
}

\author{
Song Mi Cho ${ }^{1 \dagger}$, Ju Yeon Park ${ }^{2 \dagger}$, Song Hee Han², Anne J. Anderson ${ }^{3}$, Kwang Yeol Yang', \\ Brian McSpadden Gardener ${ }^{2,4}$ and Young Cheol Kim ${ }^{2 *}$ \\ ${ }^{1}$ Department of Floriculture, Chunnam Techno College, Jeonnam 516-911, Korea \\ ${ }^{2}$ Institute of Environmentally-Friendly Agriculture, Chonnam National University, Gwangju 500-757, Korea \\ ${ }^{3}$ Department of Biology, Utah State University, Logan, UT 84322-5305, USA \\ ${ }^{4}$ Department of Plant Pathology, The Ohio State University, OARDC, 1680 Madison Avenue, Wooster, Ohio 44691, USA \\ (Received on May 11, 2011; Revised on July 21, 2011; Accepted on July 21, 2011)
}

\begin{abstract}
Root colonization of Arabidopsis thaliana with Pseudomonas chlororaphis $\mathrm{O6}$ induces systemic tolerance against diverse pathogens, as well as drought and salt stresses. In this study, we demonstrated that 11 genes in the leaves were up-regulated, and 5 genes were down-regulated as the result of three- to five-days root colonization by $P$. chlororaphis O6. The identified priming genes were involved in cell signaling, transcription, protein synthesis, and degradation. In addition, expression of selected priming genes were induced in $P$. chlororaphis O6colonized plants subjected to water withholding. Genes encoding defense proteins in signaling pathways regulated by jasmonic acid and ethylene, such as VSP1 and PDF1.2, were additional genes with enhanced expression in the $P$. chlororaphis O6-colonized plants. This study indicated that the expression of priming genes, as well as genes involved in jasmonic acid- and ethylene-regulated genes may play an important role in the systemic induction of both abiotic and biotic stress due to root colonization by $P$. chlororaphis 06 .
\end{abstract}

Keywords : disease defense, drought stress, induced systemic resistance, priming

Induced resistance or tolerance against abiotic and biotic stresses is stimulated in plants by two systems. In systemic acquired resistance (SAR), plants develop a broad spectrum of systemic resistance against plant diseases upon pathogen attack. SAR involves elevated salicylic acid (SA) levels and both local and systemic accumulation of pathogenesisrelated (PR) proteins (Van Loon et al., 2006). Expression of PR genes, PR-1 in particular, is used as a marker for SAR induction (Durrant and Dong, 2004) and a key regulatory

\footnotetext{
*Corresponding author.

Phone) +82-62-530-2071, FAX) +82-62-530-0208

E-mail)yckimyc@chonnam.ac.kr

The authors are equally contributed to this work
}

protein is NPR1 (Pierterse and Van Loon, 2004). Acibenzolar-S-methyl is a chemical that activates the SAR pathway (Bostock, 2005).

Colonization of roots by microbes also elicits systemic resistance against abiotic stresses and a broad spectrum of diseases caused by bacterial, fungal, and viral pathogens (Kim et al., 2011). Induced systemic resistance (ISR) causes the plant to induce different array of genes than SAR. One rhizobacterium, Pseudomonas chlororaphis O6, induces ISR for many plant diseases and enhanced drought tolerance (Han et al., 2006; Kim et al., 2004a; Ryu et al., 2007; Spencer et al., 2003). Three days of root colonization by $P$. chlororaphis $\mathrm{O6}$ reduces opening of leaf stomata (Cho et al., 2008), thereby demonstrating a rapidly induced systemic effect.

Enhanced plant gene activation was observed in oilseed rape treated with the ISR-inducers $P$. thivervalensis MLG45 and Bacillus amyloliquefaciens (Carieaux et al., 2003; Sarosh et al., 2009), in response to abiotic stress and after challenge by insects (Conrath et al., 2002). Differential expressed cucumber genes were induced in P. chlororaphis O6-colonized cucumber after challenge with the fungal pathogen Corynespora cassicola (Kim et al., 2004a). One induced plant gene encoding galactinol synthase (CsGolS1), when over expressed in tobacco, increases galactinol levels, enhances disease resistance against Botrytis cinerea and Pectobacterium carotovorum, and provides drought and salinity tolerance (Kim et al., 2008). Another study of plants inoculated with the ISR-inducer $P$. fluorescens WCS 417r, showed 81 genes to increase in expression after challenge inoculation with the bacterial speck pathogen $P$. syringae pv. tomato (Verhagen et al., 2004). Few changes in gene expression were noted in plants colonized by $P$. fluorescens WCS 417r without pathogen challenge (Van Wees et al., 1999; Verhagen et al., 2004). This enhanced gene activation in the colonized plants by ISR-inducing rhizobacteria is referred to as priming. However, the plant 
genes that prime for induced defense are not known so far.

The main objective of this study was to identify and characterize genes involved in priming for ISR induced by root colonization with $P$. chlororaphis O6. The priming genes in Arabidopsis thaliana were identified using a differential gene expression technique in plants at three and five days after root colonization by $P$. chlororaphis. In addition, the effects of water withholding on abundance of the identified priming genes were examined. For comparison the effect of root colonization on induction of known defense signal pathway marker genes were studied. This study indicated that root colonization of Arabidopsis by $P$. chlororaphis $\mathrm{O} 6$ stimulated an array of priming genes, and confirmed increased expression of defense genes regulated by the jasmonic acid- and ethylene-signaling pathways.

\section{Materials and Methods}

Plant materials and growth conditions. The parental $A$. thaliana ecotype Columbia (Col-0) was obtained from the Ohio State University Stock Center, Ohio State University, Columbus, $\mathrm{OH}$, USA. The plants were grown in a soil-less mixture. All seeds were surface-sterilized by 2 minutes of soaking in $70 \%$ ethanol, followed by 20 minutes of soaking in $1 \%$ sodium hypochlorite. The washed and sterile seeds were then planted in a sterile soil-less medium (peat moss: vermiculite: perlite, $7: 3: 3 \mathrm{v} / \mathrm{v}$ ) using $500 \mathrm{~cm}^{3}$ of the medium in a $10.5 \times 10.5 \times 9 \mathrm{~cm}$ pot, with $15-30$ seeds per pot. These seedlings were watered with $20 \mathrm{ml}$ of sterile water per pot every two days. The seedlings were grown with a 16-h-light/8-h-dark cycle under 40-W fluorescent lights (2,000 lux, $80 \mu \mathrm{mol}$ photons $\left.\mathrm{m}^{-2} \mathrm{~s}^{-1}\right)$. The temperature was maintained at $22 \pm 1{ }^{\circ} \mathrm{C}$ with a relative humidity of $50-60 \%$.

Bacterial strains and culture conditions. The root colonizing bacterium, $P$. chlororaphis O6 (Spencer et al., 2003), was stored at $-80^{\circ} \mathrm{C}$ in Luria-Bertani (LB) broth containing $20 \%$ glycerol. To prepare the inoculum, cells were grown overnight in Kings medium B broth, pelleted by centrifugation at $10,000 \times \mathrm{g}$ for $10 \mathrm{~min}$, washed once with sterile water, and suspended in sterile water to a concentration of $1 \times 10^{8}$ colony forming units $(\mathrm{cfu}) / \mathrm{ml}$ adjusted OD600 $\mathrm{nm}$ $=0.1$.

Assessment of timing of onset and longevity of ISR. The roots of two week-old pot-grown Arabidopsis seedlings were inoculated by the addition of $35 \mathrm{ml}$ of suspensions of P. chlororaphis $\mathrm{O} 6$ at $1 \times 10^{8} \mathrm{cfu} / \mathrm{ml}$. Sterilized water was applied to the roots of the control plants. At defined times after root treatment, the Arabidopsis plants were challenged with Pectobacterium carotovorum subsp. carotovorum strain
SCC 1 or water as a negative control onto a leaf as described previously (Han et al., 2006).

Assessment of differential gene expression. Plant genes that were differentially expressed in the leaves after rhizosphere colonization by $P$. chlororaphis $\mathrm{O} 6$ were detected by a PCR-based method using annealing controlled primers (ACPs). Total RNAs were prepared from the entire leaves of three pot-grown seedlings harvested three and five days after either the inoculation of the roots with $P$. chlororaphis O6, or simple treatment with water. The leaves were immediately frozen in liquid nitrogen, and total RNAs were extracted with an RNeasy plant mini kit (cat. no. 74904; QIAGEN). First-strand cDNA was generated by reverse transcription. First-strand cDNAs were diluted by the addition of ultra-purified water, then stored at $-20^{\circ} \mathrm{C}$ until being used in a GeneFishing ${ }^{\mathrm{TM}}$ (Seegene, Seoul, South Korea) ACP-PCR system (Kim et al., 2004b). ACP-PCR was conducted at $50^{\circ} \mathrm{C}$ for one cycle in a final reaction volume of $20 \mu \mathrm{l}$ containing 3-5 $\mu \mathrm{l}$ (about $50 \mathrm{ng}$ ) of diluted first-strand cDNA, $1 \mu \mathrm{l}$ dT-ACP2 $(10 \mu \mathrm{M}), 1 \mu 110 \mu \mathrm{M}$ arbitrary ACP, and $10 \mu 1$ \#2 Master Mix (Seegene, Seoul, South Korea). The amplified PCR products were separated in $2 \%$ agarose gel stained with ethidium bromide. The differentially expressed bands in plant samples after rootcolonization of $P$. chlororaphis $\mathrm{O} 6$ were re-amplified and extracted from the gel using a GENCLEAN II Kit (Q-BIO gene, Carlsbad, CA), and directly sequenced with an ABI PRISM 3100-Avant Genetic Analyzer (Applied Biosystems, Foster City, CA).

\section{Assessment of transcript level using quantitative reverse} transcription polymerase chain reaction (qRT-PCR). For quantitative differential expression of the selected genes (DEG), RT-PCR analysis was performed using with a QuantiTect SYBR green reverse transcription kit (cat. no.204243; QIAGEN Inc., Valencia, CA) was employed and total RNAs were extracted from leaves of control and ISR-induced plants as described above section. Briefly, the roots of two week-old pot-grown Arabidopsis seedlings were inoculated by the addition of $35 \mathrm{ml}$ of suspensions of $P$. chlororaphis $\mathrm{O} 6$ at $1 \times 10^{8} \mathrm{cfu} / \mathrm{ml}$. Sterilized water was applied to the roots of the control plants. Seven days after root treatment, plants grown under pot conditions were exposed to drought stress by withholding water for defined times. Primers for five of the ACP-PCR-detected genes were designed to yield PCR products of lengths between 150-200 bp. The primer pairs employed in the RT-PCR studies are provided in Supplemental Table 1. The controls consisted of the omission of one of the primers and analysis of the RNA without reverse transcription. Because the transcript levels of the Arabidopsis $\beta$-actin gene were not 
Table 1. Arabidopsis genes detected by ACP-based PCR as being differentially regulated in plant root colonized with Pseudomonas chlororaphis $\mathrm{O6}$

\begin{tabular}{|c|c|c|}
\hline Functional category & Representive gene name & GenBank Accession number \\
\hline \multicolumn{3}{|l|}{ Up-regulated } \\
\hline IAA synthesis & Nitrilase 1 (NIT1)(At3g44310) & NM_180680 \\
\hline \multirow[t]{2}{*}{ Stress response } & Cold-responsive protein (cor15a)(At2g42540) & NM_180040 \\
\hline & Developing seed related cDNA clone (M77F05STM) & BE530495 \\
\hline RNA-binding protein & mRNA-binding protein, putative (At3g63140) & NM_116179 \\
\hline Transcription & (C3HC4-type RING finger) family protein (At5g63780) & NM_125773.2 \\
\hline Protein synthesis & 40S ribosomal protein S7 (RPS7B) (At3g02560) & NM_111124.2 \\
\hline Photosynthesis & Chlorophyll A-B binding protein 4 precursor homolog (At3g47470) & AY093080.1 \\
\hline Protein degradation & Cysteine proteinase (RD21A)/thiol protease (Atlg47128) & NM_103612.2 \\
\hline Signaling & $\mathrm{KCBP}$ interacting $\mathrm{Ca}^{2+}$-binding protein $(\mathrm{KIC}) \mathrm{mRNA}$ & AY363866.1 \\
\hline \multirow[t]{2}{*}{ Unknown } & Expressed protein (At5g19240) & NM_121929.2 \\
\hline & At5g19240 gene & BT0045891.1 \\
\hline \multirow[t]{2}{*}{ Down-regulated } & & BE530495 \\
\hline & Developing seed Arabidopsis thaliana cDNA clone & \\
\hline Chlorophyll synthesis & Photochlorophyllide reductase precursor (At4g27440) & AY081465.1 \\
\hline \multirow[t]{3}{*}{ Photosynthesis } & Lhcb4.2 protein & AF134127.1 \\
\hline & Protodermal factor 1 (PDF1) (At2g42840) & NM_129845.2 \\
\hline & Acyl carrier family protein/ACP family protein (At4g25050) & NM_118637.2 \\
\hline
\end{tabular}

altered under the conditions employed herein, these transcript levels were used to normalize the results for each gene. The comparative CT method ( $2^{-\triangle \Lambda C T}$ method) was used to determine the expression level of analyzed genes (Livak and Schmittgen, 2001). Fold units of change in expression were calculated by dividing the normalized expression for genes in plants colonized with $P$. chlororaphis $\mathrm{O} 6$ by the normalized expression values for the genes in the untreated controls. The results are expressed as the means and standard deviations of three replicates.

Data analysis. Data were analyzed by ANOVA using IBM SPSS Statistics version 19 (IBM Corporation, Somers, NY, USA). The significance of the effects of $P$. chlororaphis $\mathrm{O} 6$ pretreatment on the target genes at different time points was evaluated by Duncan's multiple range test $(\mathrm{P}<0.05)$.

\section{Results}

ISR induction by root colonization with $P$. chlororaphis O6. The induction of ISR for a soft rot bacterial pathogen was observed at three days after root-colonization of $P$. chlororaphis $\mathrm{O} 6$ and reached maximal level after seven days of the root colonization with O6 strain. The ISR activity was maintained at this level up to 15 days after $P$. chlororaphis O6 treatment, and then gradually declined over time (Fig. 1).

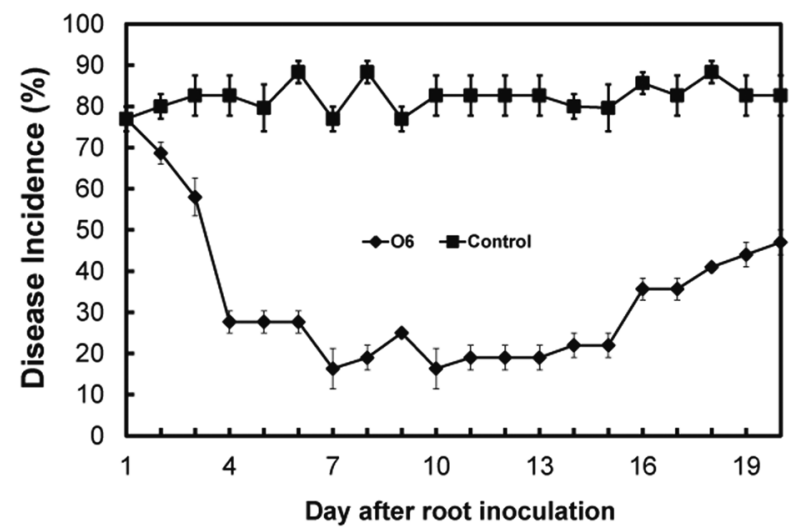

Fig. 1. Sustained ISR in $A$. thaliana upon root colonization with $P$. chlororaphis O6. Seedlings grown in pots were inoculated with $P$. chlororaphis O6 (O6) or water as a control (Control). At defined times after root treatments, leaves were challenged with the soft-rot, pathogen Pectobacterium carotovorum $\mathrm{SCC} 1$ and disease was assessed 2 days later. Three independent experiments were conducted with 3 plants/treatment. Standard errors in the assessment of the extent of disease are shown.

Identification of ISR-specific genes. The use of 120 random ACP primer pairs revealed 16 potential genes with different product intensity from RNA pooled from isolations from plants three and five days after root colonization with $P$. chlororaphis $\mathrm{O} 6$ as compared with control plants that lacked this inoculation (Fig. 2A and 2B). The transcript levels of the Arabidopsis $\beta$-actin gene did not 


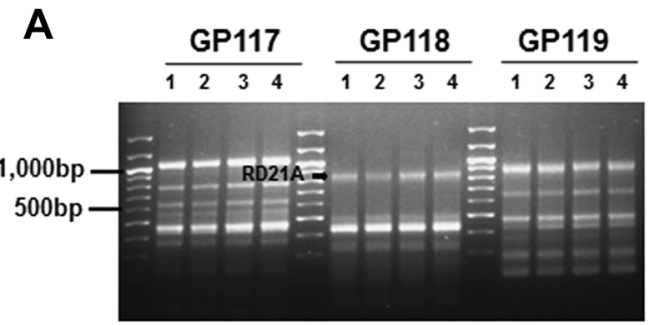

B

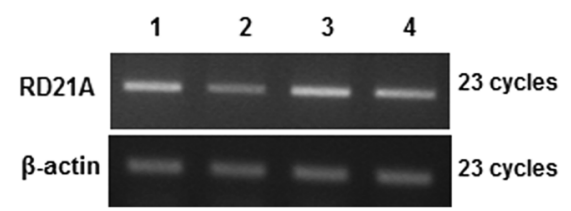

Fig. 2. Identification of differentially expressed genes (DEGs) in Arabidopsis thaliana leaves upon root colonization by $P$. chlorororaphis O6. (A). A representative agarose gel showing product formation. The two-stage PCR amplification was performed using different arbitrary 10-mer ACPs (GeneFishing ${ }^{\mathrm{TM}}$ DEG GP1 - DEG GP119) in combination with oligo dT ACP2. Lanes 1 and 2, ACP-PCR analysis from RNAs extracted 3 and 5 days from plants treated with water; and lanes 3 and 4, ACPPCR analysis from RNAs extracted 3 and 5 days after root inoculation with $P$. chlororaphis 06 . The arrow indicates the product corresponding to expression of the gene encoding RD21A transcripts in extracts from plants after root colonization by $P$. chlororaphis O6. (B) RT-PCR confirmation of induced expression from the gene encoding RD21A. Expression from the actin gene is shown to reveal equal loading of each lane.

show any major changes with these conditions (Fig. 2B), thus making it appropriate to use in normalization of expression. Table 1 shows the nature of the genes showing differential expression based on their deduced peptide moieties. Genes with increased and decreased expression were noted and they encoded a variety of functions in the plant cell. The stress responsive genes encoded proteins associated with the activity of plant growth regulators [IAA (NIT1) and ABA (Atcor15a)], the salt stress-associated protease (RD21a), a ring finger protein (At5g63780), and a calcium binding protein (KIC) were selected for further investigated. Down-regulated genes encoded a protochlorophyllide reductase precursor (At4g27440), Lhcb4.2 protein, protodermal factor 1 (PDF1), and an acyl carrier protein/ACP family protein.

Confirmation of ACP Data by Real-Time RT-PCR. Examination of transcript levels from five of these potential priming genes confirmed their expression as a consequence of colonization by $P$. chlororaphis O6. Expression of the selected DEG genes showed unique transcript patterns. For the gene encoding NIT1, maximum expression was observed five days after root colonization whereas for the
A

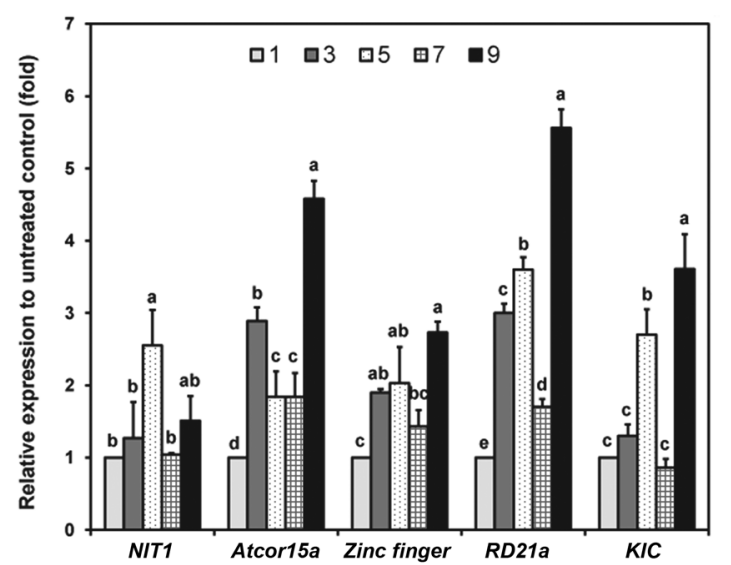

B

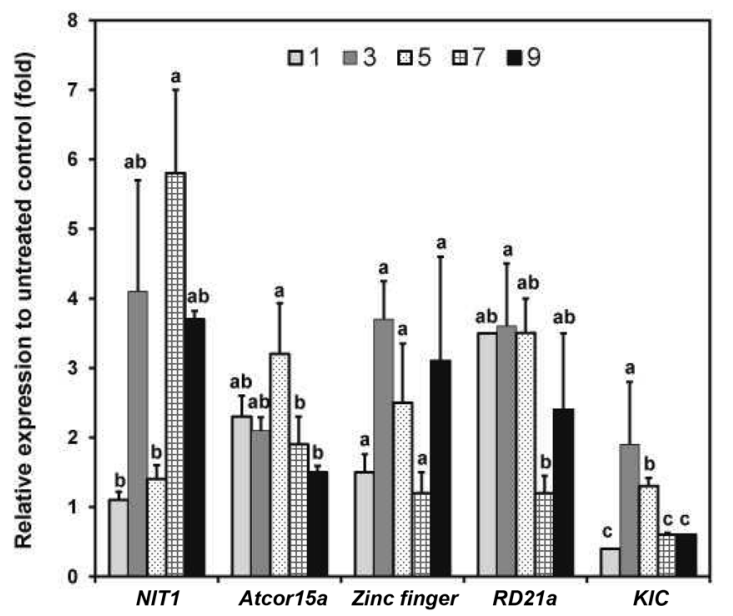

Fig. 3. Transcriptional expression of the selected genes in plants with and without root colonization by $P$. chlororaphis $\mathrm{O} 6$ under normal growth condition (A) or under water withholding (B). Transcript levels in leaves for selected genes as determined by quantitative RT-PCR for RNAs harvested from plants with and without root colonization by $P$. chlororaphis $\mathrm{O6}$, and with and without water withholding for $1,3,5,7$, and 9 days. The data are the mean fold changes \pm standard errors from three independent replicates for expression levels of each gene in plants colonized with $P$. chlororaphis O6 relative to untreated controls. Data showing the same letter are not significantly different at $\mathrm{P}<0.05$.

other genes the maximum response occurred later at nine days (Fig. 3A).

Effect of drought stress on expression of genes primed by root colonization by $\boldsymbol{P}$. chlororaphis 06 . We examined whether the selected genes were regulated by drought and whether root colonization by $P$. chlororaphis $\mathrm{O} 6$ exerted a priming effect on their expression upon the abiotic stress of water withholding (Fig. 3B). Water withholding of plants with roots colonized by $P$. chlororaphis O6, resulted significant increases in transcripts from four of the genes over drought-stressed control plant, with exception of the gene encoding $\mathrm{KIC}$. In colonized plants expression was 
A.

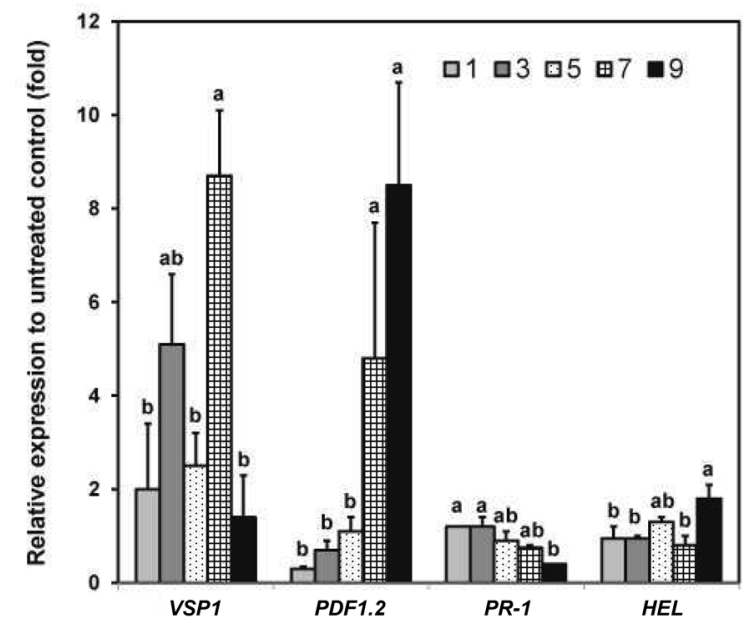

B.

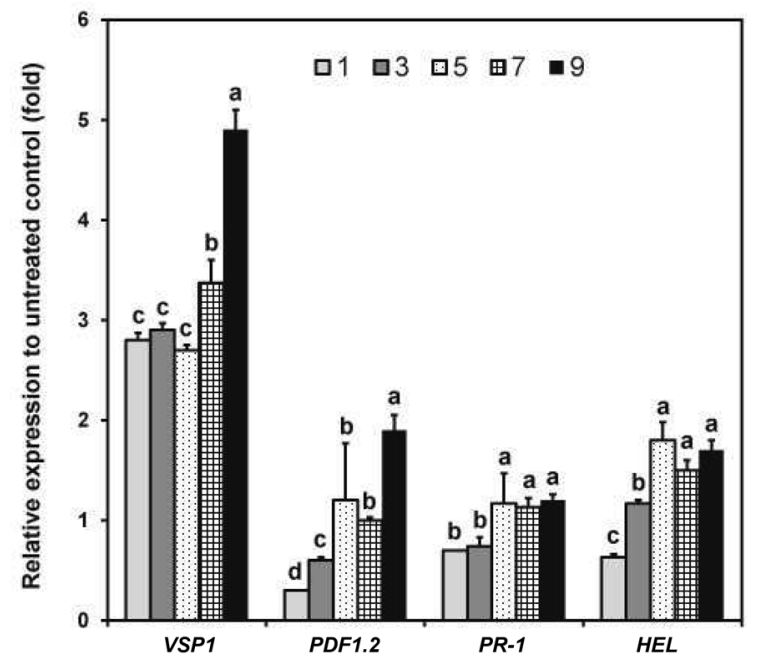

Fig. 4. Transcriptional expression of defense marker genes Arabidopsis in plants grown with and without root inoculation of P. chlororaphis $\mathrm{O} 6$ under normal growth condition (A) or water withholding condition (B). Transcript levels in leaves were determined by quantitative RT-PCR based with RNAs harvested from plants with and without root colonization by $P$. chlororaphis $\mathrm{O6}$, and with and without water withholding for 1, 3, 5, 7, and 9 days. The data are the mean fold changes with standard errors for three independent replicates. Data showing the same letter are not significantly different at $\mathrm{P}<0.05$.

increased more at 3 and 7 days after drought treatment for the NIT1, Zinc finger, and RD21a genes, and at 5 days for Atcor15A. Expression of the KIC gene showed a trend for reduced expression in colonized plants subjected to waterwithholding (Fig. 3B). These results indicated that specific genes showed a priming effect for $P$. chlororaphis O6induced drought tolerance.

Effect of $P$. chlororaphis $\mathrm{O6}$ on expression patterns of Arabidopsis defense-related genes. The expression of authenticated defense marker genes was monitored under identical conditions as above (Fig. 4A and 4B). Root colonization by $P$. chlororaphis $\mathrm{O} 6$ in normal grown plants significantly increased transcript accumulation of defense marker genes encoding PDF1.2 and VSP1 associated with the jasmonic acid and ethylene pathway. Transcripts from the ethylene sensitive $H E L$ were slightly increased upon root colonization of $P$. chlororaphis $\mathrm{O} 6$ at later time points (Fig. $4 A)$. However, transcription of the SAR marker gene $P R-1 a$ was slightly decreased.

Significant increase in VSP1 expression was observed in water limited plants pretreated with $P$. chlororaphis $\mathrm{O} 6$ over drought-stressed control plant (Fig. 4B). Similarly transcripts levels for $P D F 1.2$ and $H E L$ were slightly increased to be maximum 9 days after water witholding. However, no significant increasing of $P R$ - $1 a$ transcript was observed (Fig. 4B). These results indicated that ethylene and jasmonic acid signal pathway played an important role in the priming effect of $P$. chlororaphis O6-induced drought tolerance.

\section{Discussion}

Root colonization of A. thaliana with P. chlororaphis $\mathrm{O} 6$ alters plant performance, improving plant growth (Ryu et al., 2007), resilience to pathogenic attack (Spencer et al., 2003) and drought and salt tolerance (Cho et al., 2008). However, molecular mechanisms involved beneficial phenomenon in plants primed by $P$. chlororaphis $\mathrm{O} 6$ awaits resolution. In this study, we conclusively demonstrated that the root inoculation of Arabidopsis with P. chlororaphis $\mathrm{O} 6$ without other stresses altered gene expression both positively and negatively early after root inoculation. Both reduction in stomatal apertures, important in drought stress tolerance, and the onset of ISR required three days after root inoculation (Cho et al., 2008). Thus, root inoculation by $P$. chlororaphis O6 rapidly induced systemic effects at the cellular and gene expression levels.

Five up-regulated priming genes were related to abiotic stresses and plant growth. The functions of NIT1 and KIC may be correlated with the improved growth, observed with P. chlororaphis $\mathrm{O} 6$ root colonization of tobacco (Kang et al., 2006; Ryu et al., 2007). NIT1 (At3g44310) encodes nitrilase 1, which releases IAA from indole-3-acetonitrile (Bartel and Fink, 1994; Bartling et al., 1992). Zhang et al., (2007) previously reported increased expression of genes encoding for nitrilases 1,2 and 3 as the result of the treatment of Arabidopsis with volatiles from a plant growth-promoting isolate of Bacillus subtilis. These volatiles included butanediol, which also is produced by $P$. chlororaphis O6 (Han et al., 2006). The nitrilase genes, along with an expansin gene, were up-regulated more markedly in the leaves than in the roots, thus suggesting that they are involved in the enhanced leaf growth observed 
in plants with roots colonized by both the Bacillus and the Pseudomonas strains.

Transcript from gene (At2g46600), encoded KIC, a Ca ${ }^{2+}$ binding protein, connected with cell division, (Bowser and Reddy, 1997; Reddy et al., 2004; Smirnova et al., 1998; Vos et al., 2000). The control of $\mathrm{Ca}^{2+}$ flux by such binding proteins may be associated with regulation of stomatal apertures (Suhita et al., 2004), which were modified by root colonization P. chlororaphis O6 (Cho et al., 2008). Previous reports indicated the gene encoding Atcor15a to be drought and cold ABA-regulated (Lin and Thomashow, 1992; Wilhelm and Thomashow, 1993). RD21a encodes a cell wall-associated cysteine proteinase that is transcriptionally regulated by high salt (Koizumi et al., 1993; YamaguchiShinozaki et al., 1992). Consequently, we propose that transcriptional induction of RD21a and Atcor 15a upon root colonization with $P$. chlororaphis $\mathrm{O} 6$ could be involved in the abiotic stress tolerance induced by $P$. chlororaphis O6colonization (Cho et al., 2008).

Our studies in tobacco (Spencer et al., 2003) demonstrated that induced resistance was correlated with increased expression of the genes $P R-\lg$ (Eyal et al., 1992), HMRG (Choi et al., 1994) and Lox (Heitz et al., 1997), thereby indicating the activation of the defense genes regulated by the ethylene- and jasmonate-regulated pathways. Other studies with Arabidopsis defense signaling mutants were verified that these pathways were required for induced resistance to pathogens (Cho et al., 2008). Our data in this paper confirmed the importance of a jasmonate-related pathway through the strong induction in plants colonized with P. chlororaphis O6 for the VSP1 and PDF1.2 genes. Although we have measured increased levels of SA in plants showing stomatal closure (Cho et al., 2008) expression from the SA-responsive gene, $P R-1 a$, was not elevated in the colonized plants up to 9 days of inoculation, perhaps as the result of antagonism between the SA and JApathways (Thaler et al., 2002).

Our findings illustrate that root colonization induced cross protection for both resistance to plant pathogens and tolerance abiotic stress. Previously tolerance to pathogens and high salt, drought, and low temperatures was found upon overexpression of genes for endochitinase and basic PR1 in pepper (Hong et al., 2005). These finding indicated that genes related to pathogen defense may play important roles also in induced tolerance to abiotic stresses, such salt and drought. Rhizobacteria-mediated ISR for abiotic and biotic stresses in plants seems to share common defense signal pathways as demonstrated in this paper. In this study, P. chlororaphis O6 colonization primed certain genes for enhanced expression when plants were subjected to the abiotic stress of water withholding. Priming effects were noted for the drought-associated genes, Atcor 15a, RD21a,
Zinc finger, and NIT1. A reverse situation, repression of expression, was noted with $K I C$. However, early priming was detected only with VSP1 when the defense genes were evaluated. Later priming was observed on days 9 of water withholding for PDF1.2. Thus, priming occurred at different times for different genes indicating complexity of regulation.

In summary, root colonization by $P$. chlororaphis $\mathrm{O} 6$ primed expression of an array of genes to show increased expression upon drought stress. To our knowledge, this is the first report on identification of plant priming genes for ISR. The priming genes are associated with the cell signaling pathways regulated by ABA, jasmonic acid, and ethylene. Our findings are consistent with the fact that Arabidopsis mutants lacking in the jasmonate signaling pathways display neither induced drought resistant nor ISR in plants colonized by $P$. chlororaphis O6 (Cho et al., unpublished). Thus, our work demonstrated that resilience to both abiotic stress and biotic challenge can result from enhanced systemic activation through root colonization by certain microbes.

\section{Acknowledgements}

This work was supported by a grant from BioGreen 21 program (code\# 2007041034032), Rural Development Administration, and supported by the World Class University project of the National Research Foundation of Korea (grant no. R32-2009-000-20047-0).

\section{References}

Alméras, E., Stolz, S., Vollenweider, S., Reymond, P., Mène-Saffrané, L. and Farmer, E. E. 2003. Reactive electrophile species activate defense gene expression in Arabidopsis. Plant $J$. 34:205-216.

Bartel, B. and Fink, G. R. 1994. Differential regulation of an auxin-producing nitrilase gene family in Arabidopsis thaliana. Proc. Natl. Acad. Sci. USA 91:6649-6653.

Bartling, D., Seedorf, M., Mithöfer, A. and Weiler, E. W. 1992. Cloning and expression of an Arabidopsis nitrilase which can convert indole-3-acetonitrile to the plant hormone, indole-3acetic acid. Eur. J. Biochem. 205:417-424.

Bostock, R. M. 2005. Signal crosstalk and induced resistance: Staddling the line between cost and benefit. Annu. Rev. Phytopathol. 43:545-580.

Bowser, J. and Reddy, A. S. N. 1997. Localization of a kinesinlike calmodulin-binding protein in dividing cells of Arabidopsis and tobacco. Plant J. 12:1429-1438.

Cartieaus, F., Thi, M.-C., Zimmerli, L., Lessard, P., Sarrobert, C., David, P., Derbaud, A., Robagliz, C., Somerville, S. and Nussaume, L. 2003. Transcriptome analysis of Arabidopsis colonized by a plant-growth promoting rhizobacterium reveals a 
general effect on disease resistance. Plant J. 36:177-188.

Cho, S. M., Kang, B. R., Han, S. H., Anderson, A. J., Park, J. Y., Lee, Y. H., Cho, B. H., Yang, K. Y., Ryu, C. M. and Kim, Y. C. 2008. 2R,3R-butanediol, a bacterial volatile produced by Pseudomonas chlororaphis O6, is involved in induction of systemic tolerance to drought in Arabidopsis thaliana. Mol. Plant-Microbe Interact. 21:1067-1075.

Choi, D., Bostock, R. M., Avdiushko, S. and Hildebrand, D. F. 1994. Lipid-derived signals that discriminate wound- and pathogen-responsive isoprenoid pathways in plants: methyl jasmonate and fungal elicitor arachidonic acid induce different 3-hydroxy-3-methyglutaryl coenzyme A reductase genes and antimicrobial isoprenoids in Solanum tuberosum L. Proc. Natl. Acad. Sci. USA. 91:329-333.

Conrath, U., Pieterse, C. M. and Mauch-Mani, B. 2002. Priming in plant-pathogen interactions. Trends Plant Sci. 7:210-216.

Durrant, W. E. and Dong, X. 2004. Systemic resistance in plants. Annu. Rev. Phytopathol. 42:185-209.

Eckardt, N. A. 2001. Auxin and the power of the proteasome in plants. Plant Cell 13: 2161-2163.

Eyal, Y., Sagee, O. and Fluhr, R. 1992. Dark-induced accumulation of a basic pathogenesis-related (PR-1) transcript and a light requirement for its induction by ethylene. Plant Mol. Biol. 19:589-599.

Han, S. H., Lee, S. J., Moon, J. H., Park, K. H., Yang, K. Y., Cho, B. H., Kim, K. Y., Kim, Y. W., Lee, M. C., Anderson, A. J. and Kim, Y. C. 2006. GacS-depedent production of 2R,3R-butanediol by Pseudomonas chlororaphis $\mathrm{O} 6$ is a major determinant for eliciting systemic resistance against Erwinia carotovora but not against Pseudomonas syringae pv. tabaci in tobacco. Mol. Plant-Microbe Interact. 19:924-930.

Heitz, T., Bergey, D. R. and Ryan, C. A. 1997. A gene encoding a chloroplast targeted lipoxygenase in tomato leaves is transiently induced by wounding, systemin, and methyl jasmonate. Plant Physiol. 114:1085-1093.

Hong, J. K., Lee, S. C. and Hwang, B. K. 2005. Activation of pepper basic PR-1 gene promoter during defense signaling to pathogen, abiotic and environmental stresses. Gene. 356:169180.

Hwang, I. T., Kim, Y. J., Kim, S. H., Kwak, C. I., Gu, Y. Y. and Chun, J. Y. 2003. Annealing control primer system for improving specificity of PCR amplification. BioTechniques 35:11801184.

Kang B. R., Yang, K. Y., Cho, B. H., Han, T. H., Kim, I. S., Lee, M. C., Anderson, A. J. and Kim, Y. C. 2006. Production of indole-3-acetic acid in the plant-beneficial strain Pseudomonas chlororaphis $\mathrm{O} 6$ is negatively regulated by the global sensor kinase GacS. Curr. Microbiol. 52:473-476.

Kim, M. S., Cho, S. M., Kang, E. Y., Im, Y. J., Hwangbo, H., Kim, Y. C., Ryu, C.-M., Yang, K. Y., Chung, G. C. and Cho, B. H. 2008. Galactinol is a signaling component of the induced systemic resistance caused by Pseudomonas chlororaphis O6 root colonization. Mol. Plant-Microbe Interact. 21:16431653.

Kim, M. S., Kim, Y. C. and Cho, B. H. 2004a. Gene expression analysis in cucumber leaves primed by root colonization with
Pseudomonas chlororaphis O6 upon challenge-inoculation with Corynespora cassiicola. Plant Biol. 6:105-108.

Kim, Y. C., Leveau, J., Gardener, B. B. M., Pierson, E. A., Pierson III, L. S. and Ryu, C. M. 2011. The multifactorial basis for plant health promotion by plant-associated bacteria. Appl. Environ. Microbiol. 77:1548-1555.

Kim, Y. J., Kwak, C. I., Gu, Y. Y., Hwang, I. T. and Chun, J. Y. 2004b. Annealing control primer system for identification of differentially expressed genes on agarose gels. BioTechniques 36: $424-426$.

Koizumi, M., Yamaguchi-Shinozaki, K., Tsuji, H. and Shinozaki, K. 1993. Structure and expression of two genes that encode distinct drought-inducible cysteine proteinases in Arabidopsis thaliana. Gene 129:175-182.

Lin, C. and Thomashow, M. F. 1992. DNA sequence analysis of a complementary DNA for cold-regulated Arabidopsis gene cor15 and characterization of the COR15 polypeptide. Plant Physiol. 99:519-525.

Livak, J. K. and Schmittgen, T. D. 2001. Analysis of relative gene expression data using real-time quantitative PCR and the $2^{-\Delta C T}$ method. Methods 25:402-408.

Pieterse, C. M. J. and Van Loon, L. C. 2004. NPR1; the spider in the web of induced resistance signaling pathways. Curr. Opin. Plant Biol. 7: 456-464.

Potter, S., Uknes, S., Lawton, K., Winter, A. M., Chandler, D., DiMaio, J., Novitzky, R., Ward, E. and Ryals, J. 1993. Regulation of a hevein-like gene in Arabidopsis. Mol. Plant-Microbe Interact. 6:680-685.

Polverari, A., Molesini, B., Pezzotti, M., Buonaurio, R., Marte, M. and Delledonne, M. 2003. Nitric oxide-mediated transcriptional changes in Arabidopsis thaliana. Mol. Plant-Microbe Interact. 12:1094-1105.

Reddy, V. S., Day, I. S., Thomas, T. and Reddy, A. S. N. 2004. $\mathrm{KIC}$, a novel $\mathrm{Ca}^{2+}$ binding protein with one EF-hand motif, interacts with a microtubule motor protein and regulates trachoma morphogenesis. Plant Cell 16:185-200.

Ryu, C. M., Kang, B. R., Han, S. H., Cho, S. M., Kloepper, J. W., Anderson, A. J. and Kim, Y. C. 2007. Tobacco cultivar variability in induction of systemic resistance against Cucumber mosaic virus and growth promotion by Pseudomonas chlororaphis O6 and its gacS mutant. Eur. J. Plant Pathol. 119:383390.

Sarosh, B. R., Danielsson, J. and Meijer, J. 2009. Transcript profiling of oilseed rape (Brassica napus) primed for biocontrol differentiate genes involved in microbial interactions with beneficial Bacillus amyloliquefaciens from pathogenic Botrytis cinerea. Plant Mol. Biol. 70:31-45.

Smirnova, E., Reddy, A. S. N., Bowser, J. and Bajer, A. S. 1998. A minus end-directed kinesin-like motor protein, KCBP, localizes to anaphase spindle poles in Haemanthus endosperm. Cytoskeleton 41:271-280.

Spencer, M., Ryu, C. M., Yang, K. Y., Kim, Y. C., Kloepper, J. W. and Anderson, A. J. 2003. Induced defence in tobacco by Pseudomonas chlororaphis strain O6 involves at least the ethylene pathway. Physiol. Mol. Plant Pathol. 63:27-34.

Suhita, D., Raghavendra, A. S., Kwak, J. M. and Vavasseur, A. 
2004. Cytoplasmic alkalization precedes reactive oxygen species production during methyl jasmonate- and abscisic acid-induced stomatal closure. Plant Physiol. 134:1536-1545.

Thaler, J. S., Fidantsef, A. L. and Bostock, R. M. 2002. Antagonism between jasmonate- and salicylate-mediated induced plant resistance: effects of concentration and timing of elicitation on defense-related proteins, herbivore, and pathogen performance in tomato. J. Chem. Ecol. 28:1131-1159.

Van Loon, L. C., Rep, M. and Pieterse, C. M. J. 2006. Significance of inducible defense-related proteins in infected plants. Annu. Rev. Phytopathol. 44:135-162.

Van Wees, S. C. M., Luijendijk, M., Smoorenburg, I., van Loon, L. C. and Pieterse, C. M. J. 1999. Rhizobacteira-mediated induced systemic resistance (ISR) in Arabidopsis is not associated with a direct effect on expression on known defense-related genes but stimulates the expression of the jasmonate-inducible gene Atvsp upon challenge. Plant Mol. Biol. 41:537-549.

Verhagen, B. W. M., Glazebrook, J., Zhu, T., Chang, H.-S., van Loon, L. C. and Pieterse, C. M. J. 2004. The trancriptome of rhizoctonia-induced systemic resistance in Arabidopsis. Mol. Plant-Microbe Interact. 17:895-908.

Vos, J. W., Safadi, F., Reddy, A. S. and Hepler, P. K. 2000. The kinesin-like calmodulin binding protein is differentially involved in cell division. Plant Cell 12:979-990.

Wilhelm, K. S. and Thomashow, M. F. 1993. Arabidopsis thaliana cor15b, an apparent homologue of cor15a, is strongly responsive to cold and ABA, but not drought. Plant Mol. Biol. 23:1073-1077.

Yamaguchi-Shinozaki, K., Koizumi, M., Urao, S. and Shinozaki, K. 1992. Molecular cloning and characterization of 9 cDNAs for genes that are responsive to desiccation in Arabidopsis thaliana: sequence analysis of one cDNA clone that encodes a putative transmembrane channel protein. Plant Cell Physiol. 33:217-224.

Zhang, H., Kim, M.-S., Krishnamachari, V., Payton, P., Sun, Y., Grimson, M., Farag, M. A., Ryu, C.-M., Allen, R., Melo, I. S. and Pare, P. W. 2007. Rhizobacteria volatile emissions regulate auxin homeostatis and cell expansion in Arabidopsis. Planta 226:839-851. 